\title{
Longitudinal assessment of airway responsiveness from 1 month to 18 years in the PIAF birth cohort
}

\author{
Desmond W. Cox ${ }^{1,2}$, Dave Mullane ${ }^{1}$, Guicheng C. Zhang ${ }^{1,3}$, Steve W. Turner ${ }^{1}$, \\ Catherine M. Hayden ${ }^{1}$, Jack Goldblatt ${ }^{1,4}$, Lou I. Landau ${ }^{1}$ and Peter N. Le Souëf ${ }^{1,5}$
}

Affiliations: 'School of Paediatrics and Child Health, University of Western Australia, Perth, Australia. ${ }^{2}$ Our Lady's Children's Hospital, Crumlin, Dublin, Ireland. ${ }^{3}$ School of Public Health, Curtin University, Perth, Australia. ${ }^{4}$ King Edward Memorial Hospital, Perth, Australia. ${ }^{5}$ Respiratory Medicine, Princess Margaret Hospital, Perth, Australia.

Correspondence: Desmond W. Cox, Our Lady's Children's Hospital, Crumlin, Dublin, Ireland.

E-mail: Des.Cox@olchc.ie

ABSTRACT The Perth Infant Asthma Follow-up (PIAF) study involves a birth cohort of unselected subjects who have undergone longitudinal assessments of airway responsiveness at 1, 6 and 12 months and 6, 11 and 18 years of age. The aim of this study was to determine the relationship between increased airway responsiveness throughout childhood and asthma in early adult life.

Airway responsiveness to histamine, assessed as a dose-response slope (DRS), and a respiratory questionnaire were completed at 1, 6 and 12 months and 6,11 and 18 years of age.

253 children were initially recruited and studied. Airway responsiveness was assessed in 203, 174, 147, 103, 176 and 137 children at the above-mentioned time points, respectively ( 39 participants being assessed on all test occasions). Asthma at 18 years was associated with increased airway responsiveness at 6, 12 and 18 years, but not during infancy (slope 0.24 , 95\% CI 0.06-0.42; $\mathrm{p}=0.01$; slope $0.25,95 \%$ CI $0.08-0.49$; $\mathrm{p}=0.006$; and slope $0.56,95 \%$ CI $0.29-0.83 ; \mathrm{p}<0.001$, respectively).

Increased airway responsiveness and its association with asthma at age 18 years is established between infancy and 6 years. We propose that airway responsiveness in early life reflects the initial airway geometry and airway responsiveness later in childhood increasingly reflects immunological responses to environmental influences.

@ERSpublications

Early-life airway responsiveness is related to inherent factors; later, environmental exposures have greater effect http://ow.ly/PDmWm

This article has supplementary material available from erj.ersjournals.com

Received: Aug 282014 | Accepted after revision: June 252015 | First published online: Oct 222015

Support statement: Supported by the National Health and Medical Research Council of Australia. Funding information for this article has been deposited with FundRef.

Conflict of interest: Disclosures can be found alongside the online version of this article at erj.ersjournals.com

Copyright OERS 2015 


\section{Introduction}

Increased airway responsiveness is one of the characteristic features of asthma [1-3]. Factors that affect airway responsiveness are still unclear, but increases in airway responsiveness in asthmatic children are likely to result from structural factors that affect airway geometry, including airway cross-sectional area and airway wall compliance [4], environmental factors that can enhance smooth muscle constriction or immunological factors that determine airway wall inflammation. Which of these factors influence airway responsiveness in asthmatic children and how these change with age is still unclear. Longitudinal measurements of airway responsiveness across childhood offer the opportunity to further knowledge of this important physiological outcome variable.

The Perth Infant Asthma Follow-up (PIAF) study is a longitudinal birth cohort of unselected subjects who have undergone repeated assessments of airway responsiveness (represented by the dose-response slope (DRS) to histamine) in infancy at 1,6 and 12 months of age and at 6,12 and 18 years of age. We recently published data from this birth cohort on lung function measurements from 1 month to 18 years [5]. We have previously shown that 1-month-old infants respond to histamine [6] and that the level of response is influenced by a family history of asthma and maternal smoking during pregnancy [7]. With follow-up of the cohort, we observed that the level of response in early infancy was the strongest early determinant of respiratory status at 6 years of age [8], but only the level of response in late infancy was linked to wheeze at 12 years [9]. Although some factors were associated with increased airway responsiveness at both 6 and 12 years of age (atopy and asthma diagnosis), other factors (exposure to tobacco smoke) were associated with increased airway responsiveness only at one time point in the same individuals [10]. Together, these observations suggest that determinants of airway responsiveness change over time, presumably due to postnatal exposures, and that the relationship between airway responsiveness in early life and airway responsiveness (and therefore asthma) in later life diminishes with increasing age. The 18-year follow-up of the PIAF cohort was recently completed and airway responsiveness to histamine was assessed in all available subjects.

The aim of this study was to investigate the relationship between increased airway responsiveness at different time points from birth and both airway responsiveness and asthma in early adulthood. Based on the possibility that environmental exposures would exert an increasing influence on airway responsiveness with increasing age, we hypothesised that 1) airway responsiveness during infancy would correlate with airway responsiveness and asthma-related outcomes at 18 years, but that the strength of the relationship would diminish with increasing age; and 2) associations between airway responsiveness during childhood and airway responsiveness and asthma-related outcomes at 18 years would show increases with increasing age.

\section{Methods}

\section{Study design and protocol}

Infants were recruited antenatally while their mothers were attending a local metropolitan antenatal clinic (Osborne Park Hospital, Perth, Australia). The recruitment process has been described in detail elsewhere [7]. In brief, normal subjects, unselected for parental history of asthma and atopy, were recruited between June 1987 and November 1990. Exclusion criteria included premature birth (infants born before 36 weeks gestation), congenital abnormalities or development of respiratory symptoms in the first month of life. Informed consent was obtained from parents and the study was approved by the medical ethics committee of Princess Margaret Hospital for Children (Perth, Australia).

Participants were followed-up at 1, 6 and 12 months of age and again at 6, 12 and 18 years of age. Assessments included measurement of lung function, airway responsiveness to histamine, skin-prick reactivity to common allergens and completion of a respiratory questionnaire. The definitions of respiratory outcomes on each questionnaire at each time point were identical. Asthma was defined as an affirmative response to the question "Do you/does your child currently have asthma diagnosed by a doctor?" Wheeze was defined as an affirmative response to the question "Do you/your child ever sound wheezy and if yes, has this been present in the past year?" Atopy was defined as at least one positive skin test and details of our skin-prick testing have been described elsewhere [10]. A positive reaction was defined as a weal $\geqslant 2 \mathrm{~mm}$ in diameter for infants and $\geqslant 3 \mathrm{~mm}$ after infancy or, in cases of dermatographism, a weal larger than the negative control. Infant atopy was defined as a positive reaction on one infant assessment. Parental asthma was defined as at least one parent ever with a history of physician-diagnosed asthma at the time of enrolment. Pulmonary function testing during childhood was measured with a portable spirometer (Pneumocheck Spirometer 6100; Welch-Allyn, Skaneateles Falls, NY, USA) in accordance with published guidelines [11] and reference ranges [12].

\section{Infant lung function testing and measurement of airway responsiveness}

These have been described in detail previously [9]. Briefly, to measure respiratory function in the infant studies, the rapid tidal volume thoracoabdominal technique was used to determine maximal flow at 
functional residual capacity ( $V^{\prime}$ maxFRC), expressed as \% predicted [13]. Respiratory function was assessed in childhood using spirometry and earlier measurements were performed prior to the publication of the American Thoracic Society guidelines [14]. The YAN technique [15] was used to measure airway responsiveness for each assessment to ensure a standardised method within the cohort. A positive response to histamine in infancy was defined as a $40 \%$ drop in $V^{\prime}$ maxFRC (provocative concentration of histamine causing a $40 \%$ fall in $V^{\prime} \operatorname{maxFRC}(\mathrm{PC} 40)$ ). A positive response to histamine in childhood was defined as a $20 \%$ fall in forced expiratory volume in $1 \mathrm{~s}$ (FEV1) (provocative concentration of histamine causing a $20 \%$ fall in FEV1). DRS was used rather than PC40, as epidemiological studies have demonstrated that the DRS is a better measure when examining the continuous relationship between increased airway responsiveness and asthma symptoms $[16,17]$. The DRS for each airway responsiveness assessment was calculated by dividing the percentage reduction in $V^{\prime} \operatorname{maxFRC}$ in infancy or FEV1 in childhood by the concentration of histamine last administered [18]. In addition, the mean DRS value over infancy was calculated and used for comparison with outcomes at 18 years.

\section{Statistical analysis}

Firstly, independent t-tests and Chi-squared testing were used to compare patient demographics of participants followed-up at 18 years with those followed-up at each time point, with those lost to follow-up and with different respiratory outcomes at 18 years. DRS was $\log _{10}$ converted for each assessment in order to have an approximate normal distribution of the values of airway responsiveness measurements. Linear regression analyses were utilised to examine the association between asthma at 18 years and the $\log _{10}$ DRS values at each time point studied and were corrected for confounders, namely age, sex, atopy both during infancy and at 18 years, parental asthma at enrolment, maternal smoking during pregnancy and FEV 1 at 18 years. We then used linear regression analyses to examine the association between the $\log _{10} \mathrm{DRS}_{\text {value at }}$ 18 years and the $\log _{10}$ DRS values at each previous assessment (including the mean DRS value over infancy), again correcting for confounders. DRS was further compared with participants with and without asthma at 18 years with nonparametric testing using Mann-Whitney U-tests. Standard statistical software was used (SPSS version 20.0; IBM, Armonk, NY, USA) and a p-value of $<0.05$ was assumed to be significant.

\section{Results}

Population

253 children were initially recruited and airway responsiveness measurements were successfully completed in $203,174,147,103,176$ and 137 children at 1, 6 and 12 months and 6, 12 and 18 years of age, respectively. At the 18-year follow-up, 150 (60\% of the original cohort) subjects attended for assessment; the mean age of the group studied at the 18-year follow-up was 18.8 years and $59 \%$ were male. Of the 150 participants assessed at 18 years, 98 (38.7\% of the original cohort) had airway responsiveness measurements at each time point except at 6 years and only 39 (15.4\% of the original cohort) had airway responsiveness measurements at all six time points. We compared the demographics for the participants followed-up at 18 years with the subjects who had airway responsiveness measurements at each time point except at 6 years, at all six time points and those not followed-up at 18 years to determine if loss to follow-up changed the profile of the cohort (table 1). There were no statistical differences between the participants followed-up at 18 years compared with those who attended for follow-up at each time point, except in respect to DRS at 12 months (30.66 versus 18.51, $\mathrm{p}=0.003$ ). However, there were statistical differences between the group followed-up at 18 years when compared with those participants not followed-up at 18 years in a number of important factors, including maternal smoking during pregnancy (24.7\% versus $42.2 \%$, respectively, $\mathrm{p}=0.003), \mathrm{FEV} 1$ ( $\mathrm{z}$-score) at 6 years $(0.17$ versus $-0.04, \mathrm{p}=0.004)$, asthma at 6 years $(19.1 \%$ versus $38.2 \%, \mathrm{p}=0.03)$ and DRS at 12 years $(3.74$ versus $18.53, \mathrm{p}=0.02$ ). DRS at age 6 years was numerically higher but not significantly so $(\mathrm{p}=0.07)$ in the group not followed-up at 18 years compared with those who were followed-up.

Atopy

At the 18-year follow-up, 142 participants successfully completed skin-prick testing and details of atopy at each previous assessment are described in table 1. Separately we examined the atopic history of only those found to be atopic at 18 years. Of the $68(47.9 \%)$ atopic subjects at 18 years, $12(17.6 \%)$ out of 68 were atopic during infancy, 23 (53.5\%) out of 43 at 6 years and 51 (79.7\%) out of 64 at 12 years.

\section{Respiratory outcomes}

Respiratory outcomes were assessed at 18 years and of the 150 subjects participating, 20 (13\%) had doctor-diagnosed asthma and $38(25 \%)$ reported wheeze in the past year. We compared the respiratory outcomes of the participants who had doctor-diagnosed asthma at 18 years $(n=20)$ with those participants who reported wheeze in the past year but did not have doctor-diagnosed asthma ( $=18)$ (table 2). The respiratory outcomes at 18 years were similar in the two groups at any time point studied except that the asthma group were more likely to be asthmatic ( $66.7 \%$ versus $17.6 \%, \mathrm{p}=0.006)$ and demonstrate airway 
TABLE 1 Patient demographics at the 18-year follow-up visit compared to those participants not followed-up at 18 years

\begin{tabular}{|c|c|c|c|c|}
\hline & $\begin{array}{l}\text { Followed-up } \\
\text { at } 18 \text { years }\end{array}$ & $\begin{array}{l}\text { Followed-up at every } \\
\text { time point except } 6 \text { years }\end{array}$ & $\begin{array}{l}\text { Followed-up at } \\
\text { every time point }\end{array}$ & $\begin{array}{l}\text { Not followed-up } \\
\text { at } 18 \text { years }\end{array}$ \\
\hline Subjects $\mathrm{n}$ & 150 & 98 & 39 & 103 \\
\hline Parental asthma ${ }^{\#}$ & $29.3(44)$ & $29.6(29)$ & $33.3(13)$ & $33.7(31 / 92)$ \\
\hline Maternal smoking during pregnancy & 24.7 (37) & $23.5(23)$ & $20.5(8)$ & $42.2(43 / 102)^{*}$ \\
\hline \multicolumn{5}{|l|}{ Outcomes during infancy } \\
\hline Atopy during infancy & $15.3(23 / 127)$ & $14.3(14)$ & $10.3(4)$ & $8.7(9 / 94)$ \\
\hline DRS at 1 month & $76.17 \pm 92.44 ; n=121$ & $77.24 \pm 92.38$ & $74.06 \pm 121.91$ & $74.62 \pm 85.08 ; n=82$ \\
\hline DRS at 6 months & $42.63 \pm 47.46 ; n=112$ & $41.81 \pm 47.02$ & $32.39 \pm 30.13$ & $46.53 \pm 80.74 ; n=62$ \\
\hline DRS at 12 months & $30.66 \pm 42.90 ; n=102$ & $29.91 \pm 43.85$ & $18.51 \pm 19.60 *$ & $25.23 \pm 40.63 ; n=45$ \\
\hline \multicolumn{5}{|l|}{ Outcomes at 6 years } \\
\hline FEV1 z-score & $0.17 \pm 1.00 ; n=80$ & & $0.17 \pm 0.95 n=38$ & $-0.44 \pm 0.86 ; n=30 *$ \\
\hline Atopy & $52.1(74 / 142)$ & $51.0(50)$ & $46.2(8)$ & $50(20 / 40)$ \\
\hline Asthma & $13.2(19 / 144)$ & $11.2(11)$ & $12.8(5)$ & $20(10 / 50)$ \\
\hline DRS & $3.74 \pm 4.23 ; n=139$ & $3.44 \pm 3.56$ & $2.01 \pm 3.08$ & $18.53 \pm 73.64 ; n=37 *$ \\
\hline
\end{tabular}

Data are presented as $\%(n), \%(n / N)$ or mean \pm SD. Forced expiratory volume in $1 \mathrm{~s}\left(F E V_{1}\right)$ z-scores were derived from previously published reference values [12]. V'maxFRC: maximal flow at functional residual capacity; LRTI: lower respiratory tract infection; DRS: dose-response slope. ${ }^{\#}$ : at least one asthmatic parent at enrolment. *: $p<0.05$.

responsiveness at 12 years ( 17.43 versus $2.62, \mathrm{p}=0.01)$ (table 2$)$. We also compared the respiratory outcomes of asthmatic participants with those without asthma at 18 years to provide stronger evidence that these participants actually had asthma. When compared with those without asthma, the participants with asthma at 18 years were more likely to have a family history of asthma, have doctor-diagnosed asthma at both the 6- and 12-year visits and demonstrate both atopy and airway responsiveness at the 6-, 12- and 18-year follow-up visits (online supplementary table S1).

DRS assessed during infancy was not associated with asthma at 18 years, but there was a strong association between DRS at 6,12 and 18 years and asthma at 18 years (fig. 1). This finding persisted when corrected for confounders (slope $0.24,95 \%$ CI $0.06-0.17$; $\mathrm{p}=0.01$; slope $0.25,95 \%$ CI $0.08-0.49$; $\mathrm{p}=0.006$; and slope $0.56,95 \%$ CI $0.29-0.83 ; \mathrm{p}<0.001$, respectively) (table 3). In addition, the significant associations remained when nonparametric Mann-Whitney U-testing was performed (data not shown). A subgroup analysis was performed on the participants who had DRS assessed at every time point except 6 years $(\mathrm{n}=98)$ and those who at DRS assessed at every time point $(n=39)$ (table 3$)$. For the subgroup who had airway responsiveness measurements at each time point except 6 years, the significant association between DRS and asthma at 18 years persisted for both DRS at 12 and at 18 years (slope $0.26,95 \%$ CI $0.04-0.47$; $p=0.02$; and slope $0.50,95 \%$ CI $0.24-0.77 ; \mathrm{p}<0.001$, respectively). There were no significant associations between DRS at any time point and asthma at 18 years in the subgroup who had airway responsiveness measurements at every time point.

\section{Tracking of airway responsiveness measurements}

DRS values at 18 years were compared with the DRS values at all the previous time points including the mean value over the first year; the only significant association observed was between DRS at 12 years and DRS at 18 years (table 4). When the subgroup of participants who had airway responsiveness measurements at each time point except 6 years $(n=98)$ was assessed, the significant association persisted. Examining the subgroup of participants who had DRS at every time point $(n=39)$, there were no significant associations found (table 4).

\section{Discussion}

This study analysed a unique dataset that has longitudinal measurements of respiratory function and airway responsiveness from early infancy to early adulthood. Our findings are the first to establish the 
TABLE 2 Patient demographics comparing those participants with doctor-diagnosed asthma with those who reported wheeze but did not have doctor-diagnosed asthma at 18 years of age

\section{Asthma at \\ 18 years}

Subjects $\mathbf{n}$
Male
Parental asthma ${ }^{\#}$
Maternal smoking during pregnar
Outcomes during infancy
V'maxFRC z-score at 1 month
LRTI in first year
Atopy in 1 st year
DRS at 1 month
DRS at 6 months
DRS at 12 months
Outcomes at 6 years
FEV 1 z-score
Atopy
Asthma
DRS
Outcomes at 12 years
FEV 1 z-score
Atopy
Asthma
DRS
Outcomes at 18 years
FEV 1 z-score
Atopy
DRS

20

$55.0(11)$

$50.0(10)$

$30.0(6)$

$-0.23 \pm 0.99$

$50.0(5 / 10)$

40.0 (8)

$47.97 \pm 49.62 ; n=13$

$27.05 \pm 27.14 ; n=17$

$22.49 \pm 23.54 ; n=14$

$-0.04 \pm 1.06 ; n=15$

$66.7(10 / 15)$

$43.8(7 / 16)$

39.40 $\pm 76.65 ; n=12$

$-0.19 \pm 0.75 ; n=18$

$88.9(16 / 18)$

$66.7(12 / 18)$

$17.43 \pm 7.44 ; n=18$

$-0.35 \pm 1.49 ; n=19$

70.0 (14)

$2.62 \pm 5.14 ; n=19$
Wheeze but no p-value asthma at 18 years

Data are presented as $\%(n), \%(n / N)$ or mean \pm SD, unless otherwise stated. Forced expiratory volume in $1 \mathrm{~s}$ (FEV1) z-scores were derived from previously published reference values [12]. $V^{\prime}$ maxFRC: maximal flow at functional residual capacity; LRTI: lower respiratory tract infection; DRS: dose-response slope. \#: at least one asthmatic parent at enrolment. ${ }^{*}: p<0.05$.

pattern of relationships between airway responsiveness and respiratory status from birth to early adulthood. In a previous study, we have shown that the level of airway responsiveness in infancy predicts asthma in young children [8], but in this follow-up of older children asthma was better predicted by later measurements of airway responsiveness.

We have previously reported that airway responsiveness to histamine is present in healthy infants shortly after birth [7] and that increased airway responsiveness in infancy correlated with asthma at 6 years, but

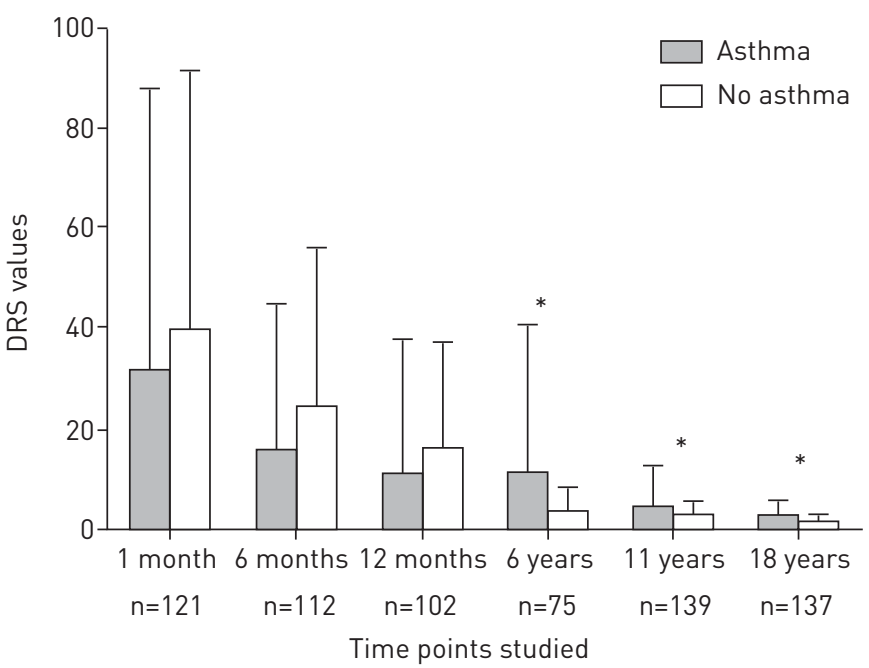

FIGURE 1 The relationship between the geometric mean dose-response slope (DRS) at each time point studied and asthma at 18 years, unadjusted for confounders. The DRS was calculated by dividing the percentage reduction in maximal flow at functional residual capacity in infancy or forced expiratory volume in $1 \mathrm{~s}$ in childhood by the concentration of histamine last administered and was then $\log _{10}$ converted. Error bars indicate $2 \mathrm{SD}$. $*$ : $p<0.05$. 
TABLE 3 The relationship between asthma at 18 years and $\log _{10}$ dose-response slope (DRS) for each time point, corrected for confounders

\begin{tabular}{|c|c|c|c|c|c|c|c|}
\hline & \multirow[t]{2}{*}{ Subjects $n$} & \multicolumn{2}{|c|}{ Followed-up at 18 years } & \multicolumn{2}{|c|}{$\begin{array}{l}\text { Followed-up at every time } \\
\text { point except } 6 \text { years }\end{array}$} & \multicolumn{2}{|c|}{$\begin{array}{l}\text { Followed-up at } \\
\text { every time point }\end{array}$} \\
\hline & & Slope $(95 \% \mathrm{CI})$ & p-value & Slope $(95 \% \mathrm{CI})$ & p-value & Slope $(95 \% \mathrm{CI})$ & p-value \\
\hline 1 month & 121 & $-0.07(-0.19-0.04)$ & 0.21 & $-0.05(-0.18-0.07)$ & 0.42 & $-0.05(-0.26-0.16)$ & 0.63 \\
\hline 6 months & 112 & $-0.08(-0.21-0.05)$ & 0.21 & $-0.05(-0.19-0.10)$ & 0.53 & $-0.11(-0.35-0.12)$ & 0.32 \\
\hline 12 months & 102 & $-0.06(-0.18-0.07)$ & 0.36 & $-0.10(-0.23-0.03)$ & 0.13 & $-0.21(-0.42-0.01)$ & 0.06 \\
\hline 18 years & 137 & $0.56(0.29-0.83)$ & $<0.001^{*}$ & $0.50(0.24-0.77)$ & $<0.001 *$ & $0.40(-0.04-0.84)$ & 0.08 \\
\hline
\end{tabular}

Confounders were age, sex, atopy both during infancy and at 18 years, parental asthma at enrolment, maternal smoking during pregnancy and forced expiratory volume in $1 \mathrm{~s}$ at 18 years. Only one earlier value of DRS was included in the model at a time. *: $p<0.05$.

correlations declined with later respiratory assessments at 12 years of age $[9,19]$. In the present study, we found that this association declined further at the 18-year follow-up. In contrast, there were significant associations between increased airway responsiveness at 6 and 12 years with asthma at 18 years. In addition, DRS values at 12 years were found to be associated with DRS values at 18 years, but earlier measurements of DRS did not. During infancy the DRS values were slightly lower in those that went on to develop asthma at 18 years (fig. 1); however there was no statistically significant difference between the two groups. Although the slopes resulting from sensitivity analysis performed are not identical, they were similar, confirming the strength of the associations reported and the robustness of the data. The factors that influence levels of airway responsiveness during infancy are not fully understood, but previous studies suggest that genetic and environmental factors act in utero to determine initial airway structure and function [7, 20-25]. In addition, there is evidence that some immunogenetic factors responsive to environmental influences may contribute to airway responsiveness and asthma at 6 and 12 years, as shown in the PIAF study [22-25], and in later childhood, as shown in another childhood cohort [26]. Although this study was not specifically designed to describe the mechanisms by which airway responsiveness evolves through childhood, our findings may suggest that intrinsic or inherent levels of airway responsiveness determine asthma in early childhood and continue to affect respiratory outcomes throughout childhood, but with increasing age, exposure to environmental factors becomes the more dominant determinant of asthma.

Previous studies have shown increased airway responsiveness in childhood to be an independent risk factor for asthma in adulthood [3, 27]. However, none of these studies measured airway responsiveness in infancy and only investigated airway responsiveness from early childhood onwards [3, 27]. Also, some studies reporting airway responsiveness in children measured airway response to bronchodilators rather than airway responsiveness to an agonist, such as histamine or methacholine [28-30], and these two forms of airway responsiveness are unlikely to be comparable. This is consistent with a recent study, which demonstrated that the wheezing phenotypes most significantly associated with airway responsiveness and

TABLE 4 The relationship between $\log _{10}$ dose-response slope (DRS) at 18 years and the $\log _{10}$ DRS for each previous time point with accounting for potential confounders

\begin{tabular}{|c|c|c|c|c|c|c|c|}
\hline & \multirow[t]{2}{*}{ Subjects $\mathrm{n}$} & \multicolumn{2}{|c|}{$\begin{array}{l}\text { Followed-up } \\
\text { at } 18 \text { years }\end{array}$} & \multicolumn{2}{|c|}{$\begin{array}{l}\text { Followed-up at every time } \\
\text { point except } 6 \text { years }\end{array}$} & \multicolumn{2}{|c|}{$\begin{array}{l}\text { Followed-up } \\
\text { at every time point }\end{array}$} \\
\hline & & Slope $(95 \% \mathrm{CI})$ & $\mathrm{p}$-value & Slope $(95 \% \mathrm{CI})$ & p-value & Slope $(95 \% \mathrm{Cl})$ & p-value \\
\hline 1 month & 121 & $-0.06(-0.14-0.02)$ & 0.15 & $-0.06(-0.15-0.03)$ & 0.21 & $-0.09(-0.25-0.08)$ & 0.51 \\
\hline 6 months & 112 & $-0.03(-0.11-0.05)$ & 0.47 & $-0.03(-0.14-0.08)$ & 0.59 & $-0.10(-0.29-0.09)$ & 0.29 \\
\hline 12 months & 102 & $0.04(-0.04-0.13)$ & 0.30 & $0.006(-0.09-0.10)$ & 0.90 & $0.07(-0.11-0.26)$ & 0.78 \\
\hline 12 years & 139 & $0.18(0.05-0.30)$ & $0.007 *$ & $0.21(0.05-0.36)$ & $0.01 *$ & $0.22(-0.13-0.58)$ & 0.08 \\
\hline
\end{tabular}

Confounding factors were age, sex, atopy both during infancy and at 18 years, parental asthma at enrolment, maternal smoking during pregnancy and forced expiratory volume in $1 \mathrm{~s}$ at 18 years. Only one earlier value of DRS was included in the model at a time. *: $p<0.05$. 
atopy commenced after 18 months of age [31]. Given the complexity of performing airway responsiveness assessments during infancy, the result of our current study suggest that such measurements may be better deferred until children reach early school-age.

Our study is unique in its longitudinal nature; extending from soon after birth, through infancy, early and mid-childhood up to early adulthood and no previous studies have reported associations with airway responsiveness over a similar timeframe. A further strength of our study is that we used the same agonist and, for all infant assessments and all assessments in children, the same techniques for measuring increased airway responsiveness in infancy and in childhood.

Given that there were a proportion of children who reported wheeze in the past year at 18 years but did not have doctor-diagnosed asthma, we examined the two groups to assess whether there were differences between them. We found that the subjects who had doctor-diagnosed asthma at 18 years were more likely to have previously demonstrated airway responsiveness and been diagnosed with asthma at 12 years, but otherwise their clinical demographics were similar. Although conclusions from this analysis should be interpreted with some caution because of the small numbers included, we postulate that those reporting wheeze were probaby asthmatic but had a milder disease phenotype as they reached adulthood, or may not have sought medical care.

Of the 253 children initially recruited, $40 \%(n=103)$ were not available at the most recent follow-up, this was mainly (90\%) due to difficulty of making contact, as very few of those contacted declined to continue the study. In addition, a much lower number of participants were recruited at 6 years when compared with other time points. The low predictive value within individuals demonstrated in this article may have been as a result of this loss to follow-up. However, a success rate of $60 \%(n=150)$ for follow-up of an 18-year longitudinal study of this kind retained sufficient power to achieve significant findings. In addition, our follow-up rates would be comparable with other similar birth cohorts assessing lung function measurements longitudinally, such as the Avon Longitudinal Study of Parents and Children [31] and Tuscon Children's Respiratory Study [27].

Only 39 participants had airway responsiveness assessed at every time point and sensitivity analysis on these subjects revealed no significant associations between DRS values at any previous time point and asthma or DRS at 18 years. Since the effect size remained unchanged, we postulate that this loss of significance is probably due to the small numbers included in the analysis. Although there were no differences at the earlier assessments between the population studied at 18 years and those followed-up at each time point, there were a number of differences with those not followed-up at 18 years. The group lost to follow-up were more likely to have a mother who smoked in pregnancy, have asthma and a lower FEV1 at 6 years (table 1). We postulate that the differences could be related to socioeconomic status, and these subjects are more likely to be lost to follow-up in longitudinal studies [32]. However, if included, these children would be more likely to demonstrate airway responsiveness and have asthma at 18 years. The associations reported in this study were on children without these significant risk factors, so by inference, the addition of these high-risk children would strengthen the associations and not reduce them. It is also acknowledged that although the rapid tidal volume thoracoabdominal technique used in this study was state-of-the art at the time, it was not volume anchored. The newer raised volume technique was not developed by the authors until later on [33]. It has previously been shown that there is within-subject variability in airway responsiveness related to the size of the subject [34]. It is also acknowledged that using $V^{\prime}$ maxFRC measurements in infancy to assess airway responsiveness has some limitations. Any small changes in FRC may be associated with large changes in $V^{\prime} \operatorname{maxFRC}$. In addition, a fall of $40 \%$ in $V^{\prime} \operatorname{maxFRC}$ would be more easily demonstrated in infants with flow limitation. While the findings of this study certainly add to our understanding of how airway responsiveness develops during infancy and childhood, we recognise that increased variability of measurements made during infancy might mean that a small (but not large) difference in infantile airway responsiveness for those destined to have asthma at 18 years might be undetected.

In conclusion, our current and previous studies on this cohort have demonstrated that the level of airway responsiveness in early life is a strong influence on asthma in young children, but that this relationship declines with increasing age when airway responsiveness measured later in childhood becomes a better predictor of future asthma. These findings may suggest that airway responsiveness in early life reflects the effects of intrinsic or inherent factors and airway responsiveness later in childhood increasingly reflects responses to environmental exposures. Further studies with a specific focus on identifying the underlying mechanisms of airway responsiveness development during childhood may shed further light on this theory and lead to more selective treatments for the complex mix of mechanisms responsible for variations in the spectrum of asthma.

\section{References}

1 O'Connor GT, Sparrow D, Weiss ST. The role of allergy and nonspecific airway hyperresponsiveness in the pathogenesis of chronic obstructive pulmonary disease. Am Rev Respir Dis 1989; 140: 225-252. 
2 Salome CM, Peat JK, Britton WJ, et al. Bronchial hyperresponsiveness in two populations of Australian schoolchildren. I. Relation to respiratory symptoms and diagnosed asthma. Clin Allergy 1987; 17: 271-281.

3 Sears MR, Greene JM, Willan AR, et al. A longitudinal, population-based, cohort study of childhood asthma followed to adulthood. N Engl J Med 2003; 349: 1414-1422.

4 Stick SM. Pulmonary physiology, airway responsiveness and asthma. Med J Aust 2002; 177: S55-S56.

5 Turner S, Fielding S, Mullane D, et al. A longitudinal study of lung function from 1 month to 18 years of age. Thorax 2014; 69: 1015-1020.

6 Lesouëf PN, Geelhoed GC, Turner DJ, et al. Response of normal infants to inhaled histamine. Am Rev Respir Dis 1989; 139: 62-66.

7 Young S, Le Souëf PN, Geelhoed GC, et al. The influence of a family history of asthma and parental smoking on airway responsiveness in early infancy. $N$ Engl J Med 1991; 324: 1168-1173.

8 Palmer LJ, Rye PJ, Gibson NA, et al. Airway responsiveness in early infancy predicts asthma, lung function, and respiratory symptoms by school age. Am J Respir Crit Care Med 2001; 163: 37-42.

9 Turner SW, Palmer LJ, Rye PJ, et al. The relationship between infant airway function, childhood airway responsiveness, and asthma. Am J Respir Crit Care Med 2004; 169: 921-927.

10 Turner SW, Palmer LJ, Rye PJ, et al. Determinants of airway responsiveness to histamine in children. Eur Respir J 2005; 25: 462-467.

11 American Thoracic Society. Standardization of spirometry - 1987 update. Am Rev Respir Dis 1987; 136: 1285-1298.

12 Knudson RJ, Lebowitz MD, Holberg CJ, et al. Changes in the normal maximal expiratory flow-volume curve with growth and aging. Am Rev Respir Dis 1983; 127: 725-734.

13 Young S, Sherrill DL, Arnott J, et al. Parental factors affecting respiratory function during the first year of life. Pediatr Pulmonol 2000; 29: 331-340.

14 American Thoracic Society. Standardization of spirometry, 1994 update. Am J Respir Crit Care Med 1995; 152: 1107-1136.

15 Yan K, Salome C, Woolcock AJ. Rapid method for measurement of bronchial responsiveness. Thorax 1983; 38: $760-765$.

16 de Meer G, Marks GB, de Jongste JC, et al. Airway responsiveness to hypertonic saline: dose-response slope or PD15? Eur Respir J 2005; 25: 153-158.

17 Abramson MJ, Saunders NA, Hensley MJ. Analysis of bronchial reactivity in epidemiological studies. Thorax 1990; 45: 924-929.

18 Turner SW, Khoo SK, Laing IA, et al. $\beta_{2}$ adrenoceptor Arg16Gly polymorphism, airway responsiveness, lung function and asthma in infants and children. Clin Exp Allergy 2004; 34: 1043-1048.

19 Turner SW, Young S, Goldblatt J, et al. Childhood asthma and increased airway responsiveness: a relationship that begins in infancy. Am J Respir Crit Care Med 2009; 179: 98-104.

20 Stick SM, Burton PR, Gurrin L, et al. Effects of maternal smoking during pregnancy and a family history of asthma on respiratory function in newborn infants. Lancet 1996; 348: 1060-1064.

21 Murdzoska J, Devadason SG, Khoo SK, et al. In utero smoke exposure and role of maternal and infant glutathione s-transferase genes on airway responsiveness and lung function in infancy. Am J Respir Crit Care Med 2010; 181: 64-71.

22 Laing IA, de Klerk NH, Turner SW, et al. Cross-sectional and longitudinal association of the secretoglobin 1A1 gene A38G polymorphism with asthma phenotype in the Perth Infant Asthma Follow-up cohort. Clin Exp Allergy 2009; 39: 62-71.

23 Laing IA, Hermans C, Bernard A, et al. Association between plasma CC16 levels, the A38G polymorphism, and asthma. Am J Respir Crit Care Med 2000; 161: 124-127.

24 Ramsay CE, Hayden CM, Tiller KJ, et al. Polymorphisms in the $\beta_{2}$-adrenoreceptor gene are associated with decreased airway responsiveness. Clin Exp Allergy 1999; 29: 1195-1203.

25 Zhang G, Hayden CM, Khoo SK, et al. Association of haplotypes of $\beta_{2}$-adrenoceptor polymorphisms with lung function and airway responsiveness in a pediatric cohort. Pediatr Pulmonol 2006; 41: 1233-1241.

26 O'Donnell AR, Toelle BG, Marks GB, et al. Age-specific relationship between CD14 and atopy in a cohort assessed from age 8 to 25 years. Am J Respir Crit Care Med 2004; 169: 615-622.

27 Stern DA, Morgan WJ, Halonen M, et al. Wheezing and bronchial hyper-responsiveness in early childhood as predictors of newly diagnosed asthma in early adulthood: a longitudinal birth-cohort study. Lancet 2008; 372: 1058-1064.

28 Dales RE, Spitzer WO, Tousignant P, et al. Clinical interpretation of airway response to a bronchodilator. Epidemiologic considerations. Am Rev Respir Dis 1988; 138: 317-320.

29 Goldstein AB, Castile RG, Davis SD, et al. Bronchodilator responsiveness in normal infants and young children. Am J Respir Crit Care Med 2001; 164: 447-454.

30 Hiatt P, Eigen H, Yu P, et al. Bronchodilator responsiveness in infants and young children with cystic fibrosis. Am Rev Respir Dis 1988; 137: 119-122.

31 Henderson J, Granell R, Heron J, et al. Associations of wheezing phenotypes in the first 6 years of life with atopy, lung function and airway responsiveness in mid-childhood. Thorax 2008; 63: 974-980.

32 Turner SW, le Souëf PN. Is patient dropout from a longitudinal study of lung function predictable and reversible? Pediatr Pulmonol 2003; 35: 29-33.

33 Turner DJ, Stick SM, Lesouëf KL, et al. A new technique to generate and assess forced expiration from raised lung volume in infants. Am J Respir Crit Care Med 1995; 151: 1441-1450.

34 Le Souëf PN, Sears MR, Sherrill D. The effect of size and age of subject on airway responsiveness in children. Am J Respir Crit Care Med 1995; 152: 576-579. 